\title{
Mechanism Research and Discussion of the Quality of Precision Machining of a Fifth-order Variable-diameter Pipe Using Abrasive Flow
}

\author{
Junye Li - Lixiong Wang - Hengfu Zhang - Jinglei Hu - Xinming Zhang* - Weihong Zhao \\ Ministry of Education, Key Laboratory for Cross-Scale Micro- and Nano-Manufacturing, \\ Changchun University of Science and Technology, China
}

The solid-liquid two-phase abrasive flow precision machining technology is widely used in aerospace, precision machinery, the automotive industry and other fields, and is an advanced manufacturing technology that effectively improves the inner surface quality of workpieces. In this paper, the fifth-order variable-diameter pipe parts are researched. By discussing the collision between the abrasive particles and the wall surface, it is revealed that the material removal of the workpiece is caused by plastic deformation, and the mechanism of precision machining of the abrasive flow is clarified. Through numerical analysis and experimental research, it is found that the incident angle can affect the precision machining quality of the abrasive flow. When the inlet velocity of the abrasive flow is $45 \mathrm{~m} / \mathrm{s}$ and the incident angle is $15^{\circ}$, the fifthorder variable-diameter pipe can obtain the best surface quality. Abrasive flow machining improves the surface quality of small holes better than that of large holes. To obtain uniform surface quality, it is necessary to use two-way machining to perform abrasive flow machining. The surface texture of the fifth-order variable-diameter pipe workpiece after precision machining by abrasive flow becomes clear and smooth, and the surface quality is significantly improved. The research results can provide theoretical guidance and technical support for the popularization and application of solid-liquid two-phase abrasive flow precision machining technology, with significant academic value and application value.

Keywords: abrasive flow precision machining; numerical analysis; variable-diameter pipe; quality control
Highlights
- The computational fluid dynamics discrete element method (CFD-DEM) coupling theory and the removal mechanism of abrasive flow polishing materials were analysed.
- The surface quality of the fifth-order variable-diameter tube after polishing by abrasive particle flow was discussed from different inlet speeds and incident angles.
- Through numerical simulation, the optimal process parameters for polishing the fifth-order variable calibre tube with abrasive flow were obtained.
- Experiments using abrasive particle flow to polish a fifth-order variable calibre tube have verified the validity and reliability of the numerical analysis.

\section{O INTRODUCTION}

With the rapid development of engineering technology, machining has begun to move from rough machining to precision and ultra-precision machining; abrasive particle flow polishing is an ultra-precision machining technology. During the abrasive flow polishing process, the abrasive is a mixture of abrasive particles and fluids, flowing through the inner hole channel or curved surface at a certain inlet speed [1] and [2]. The basic working principle of abrasive particle flow is to squeeze the abrasive fluid with specific rheological characteristics to make it flow through the closed flow channel constrained by the fixture and the workpiece. Precision machining is realized under the action of micro-cutting to obtain the inner surface of the part with high precision [3] to [5]. As abrasive tools, the abrasive particles continuously collide with the surface to be processed and finally achieve the purpose of polishing the surface to be processed. The abrasive is the most important processing medium in the process of abrasive flow polishing, and it is also the main factor controlling the polishing effect [6] to [8]. For the study of the flow field, a numerical simulation method is generally used. Traditional computational fluid dynamics (CFD) has certain limitations. The velocity of the fluid at the wall surface is zero by default, and the solid phase abrasive particles are mostly calculated by pseudo-fluid in the two-phase flow, so the velocity of the abrasive particles impacting the wall surface is also zero [9] to [11]. In the actual processing, the abrasive particles enter the fluid boundary layer and maintain the original motion state under the action of inertia, and then impact the wall surface to produce the cutting effect [12] to [14]. Discrete element method simulation of abrasive flow polishing process mainly refers to simulating the flow state of abrasive particles in the workpiece cavity and analysing the dynamic parameters between the abrasive particles and between the abrasive particles and the workpiece, so 
as to realize the quantitative and numerical analysis of the machining process [15] to [17].

Because abrasive flow precision machining technology can effectively deburr, polish, and round the workpiece, the workpiece can obtain higher precision; therefore, many scholars have conducted in-depth research on it [18] to [20]. Mohanty et al. [21] used the computational fluid dynamics-discrete element method (DEM-CFD) method to predict the flow behaviour of packed beds. Random filling was performed using the discrete element method (DEM) technology, and the flow of the packed bed was studied by a single-phase laminar flow model. The flow follows an oscillation mode with a similar radial void. The experimental results show that DEM and CFD simulations can predict the flow behaviour in packed beds. Kim et al. [22] studied the effects of various abrasive flow machining process parameters are investigated for holes intersecting at a right angle with offset. Through the use of the L8 (2-(5)) orthogonal array to experimentally study the flow distance, abrasive particle size, abrasive concentration, abrasive viscosity, and flow velocity of AL6061 specimens. The results show that the flow distance has the greatest effect on the removal of burrs, and the flow velocity has the least effect on the removal of burrs. Li et al. [23] used the mesoscopic scale of particles as a research object in the molecular dynamics theory, combined with hydrodynamics, to carry out the numerical simulations. They analysed the collision between abrasive particles and wall surface, studied polishing temperature and different cutting angles of the abrasive flow precision machining. They also compared their work with experimental data. Their results show that the optimal temperature range between abrasive particle and wall collision processing is $300 \mathrm{~K}$ to $310 \mathrm{~K}$. The small cutting angles can improve the surface quality and reduce the inside defects of the workpiece. In the ultra-precision machining process, the economics and sustainability of production also need to be considered. Tan et al. [24] adopted the new machining technology of ultrasonic elliptical vibration-assisted cutting (UEVC) to solve the processing difficulties of Ti-6Al-4V alloy in traditional dry ultra-precision cutting (TDUC) process. It not only improves the surface quality of the workpiece but also provides a sustainable process. Chetan et al. [25] compared the technology of lowtemperature cooling and low-temperature treatment with the cooling method of MQL based on $\mathrm{Al}_{2} \mathrm{O}_{3}$ nanoparticles during the turning of nickel-based Nimonic 90 alloy. Based on the degree of wear of the tool face and the machining quality of the workpiece surface, it was concluded that a low-temperature cooling environment is the best way to process Nimonic 90 alloy.

Based on discrete element theory and method, this paper constructs a numerical analysis model of solid-liquid two-phase flow of $5^{\text {th }}$ order variablediameter pipe parts and performs numerical simulation analysis under CFD-DEM coupled field conditions to discuss the influence of coupling fields, such as fluiddynamic pressure and total abrasive energy, on the polishing quality of $5^{\text {th }}$ order variable-diameter pipe. Experiments on abrasive flow precision machining were carried out, and the surface quality of the inner surface before and after polishing is compared and analysed to study the surface quality effect of the abrasive flow precision machining of the variable diameter pipe parts. The research results can provide theoretical guidance and technical support for the popularization and application of solid-liquid twophase abrasive flow precision machining technology.

\section{STUDY ON MATERIAL REMOVAL MECHANISM OF ABRASIVE FLOW PRECISION MACHINING}

To study the effect of abrasive particles on the wall surface of the $5^{\text {th }}$ order variable-diameter pipe in the process of abrasive flow precision machining, it is necessary to visually calculate and analyse the movement process of the abrasive particles in the workpiece. In the process of abrasive flow precision machining, the abrasive particles interact with the workpiece wall surface. By analyzing the removal of single abrasive particles on the wall material of the workpiece, the wear degree of the abrasive particles on the inner surface of the workpiece is discussed, the material removal mechanism of abrasive particles erosion on workpiece wall can be obtained.

\subsection{CFD-DEM Coupling Theoretical Model}

In solid-liquid two-phase flow, in addition to the transfer of heat, momentum and mass inside the liquid phase, there is also a transfer of heat, momentum and mass between the fluid and the particles. This section mainly describes the coupled theoretical model of computational fluid dynamics (CFD) and discrete element method (DEM).

\subsubsection{CFD-DEM Resistance Model}

The model is suitable for handling abrasive particles in two situations: 
(1) Abrasive particles of the same size or smaller in volume than the fluid grid unit;

(2) Abrasive particles whose fluid parameters (speed, density, viscosity, etc.) vary substantially constantly. The resistance coefficient $C_{D}$ depends on the Reynolds number $R_{e}$ :

$$
C_{D}=\left\{\begin{array}{cc}
R_{e}=\frac{\alpha \rho L|v|}{n}, & R_{e} \leq 0.5 \\
\frac{24}{R_{e}} & 0.5<R_{e} \leq 1000, \\
\frac{24\left(1.0+0.25 R_{e}^{0.687}\right)}{R_{e}} & R_{e}>1000 \\
0.44 &
\end{array}\right.
$$

where $C_{D}$ is the resistance coefficient; $R_{e}$ is the Reynolds number; $\rho$ is the fluid density; $n$ is the viscosity of the fluid; $L$ is the diameter of the abrasive ball; $v$ is the relative velocity between the abrasive particles and the fluid; $\alpha$ is the free volume of the CFD grid element. In addition to resistance, the inherent buoyancy of the abrasive particles must also be considered. The formula for calculating buoyancy is:

$$
F_{B}=\rho g V .
$$

Generally, for Lagrangian coupling, this improved resistance law can be used to consider the effect of abrasive load; in the Eulerian coupling, the abrasive particle load needs to consider this effect by combining the volume fraction method.

\subsubsection{CFD-DEM Lift Model}

(1) Saffman Lift Model

Lifting force occurs when the abrasive particles are in a high-speed fluid, and the speed gradient causes a pressure difference on the surface of the abrasive particles. Saffman [26] lift can be expressed as:

$$
F_{\text {saff }}=1.61 d_{p}^{2}\left(\mu_{f} \rho_{f}\right)^{1 / 2}\left|\omega_{c}\right|^{-1 / 2}(u-v) \omega_{c} .
$$

Among them, the velocity of the fluid is $\omega_{c}=\nabla \cdot u$.

However, this simple model must be very slow at the shear flow rate and satisfy the following conditions:

$$
\left\{\begin{array}{l}
\operatorname{Re}_{s}=\frac{|u-v| d_{p}}{v}<1 \\
\operatorname{Re}_{G}=\frac{|d y / d y| d_{p}^{2}}{v}<1 \\
\operatorname{Re}_{\Omega}=\frac{\left|0.5 \omega_{c}-\omega_{p}\right| d_{p}^{2}}{v}<1 \\
\varepsilon=\frac{\operatorname{Re}_{G}^{1 / 2}}{\operatorname{Re}_{s}}>1
\end{array},\right.
$$

where $\omega_{p}$ is the angular velocity of the abrasive particles.

To overcome the above constraints, Mei

[27] proposed two correlation equations $\left(0.1<\operatorname{Re}_{s}<100\right)$ :

$$
\left\{\begin{array}{rlrl}
\frac{F_{L, \text { mei }}}{F_{\text {saff }}}=\left(1-0.3314 \alpha^{1 / 2}\right) \exp \left[-\frac{\mathrm{Re}_{s}}{10}\right]+ & & \\
& +0.3314 \alpha^{1 / 2} & \mathrm{Re}_{s} \leq 40 \\
\frac{F_{L, \text { mei }}}{F_{\text {saff }}}=0.0524\left(\alpha \mathrm{Re}_{s}\right)^{1 / 2} & \mathrm{Re}_{s}>40
\end{array}\right.
$$

This correlation equation needs to satisfy a limited shear rate: $\alpha=1 / 2 \operatorname{Re}_{s} \varepsilon^{2}$ where $0.005<\alpha<0.4$.

(2) Magnus Lift Model

Magnus lift [27] is the lift due to the spin of the abrasive particles. The relationship between the resistance coefficient of the sphere and the Reynolds number can be expressed as:

$$
\left\{\begin{array}{l}
F_{\text {Mag }}=0.125 \pi d_{p}^{3} \rho_{f} \frac{\operatorname{Re}_{s}}{\operatorname{Re}_{\Omega}} C_{L}\left(0.5 \omega_{c}-\omega_{p}\right)(u-v) \\
C_{L}=0.45+\left[\frac{\operatorname{Re}_{\Omega}}{\operatorname{Re}_{s}}-0.45\right] \exp \left(-0.0568 \operatorname{Re}_{\Omega}^{0.4} \operatorname{Re}_{s}^{0.3}\right)
\end{array} .\right.
$$

This model is still applicable to abrasive particles with Reynolds numbers up to 2000 .

\subsection{Material Removal Mechanism of Abrasive Particles on Walls Impacted by Different Materials}

The workpiece material used in the numerical calculation was stainless steel; to obtain abrasive particles with better polishing effect, the abrasive particles of three commonly used materials were selected in this article: $\mathrm{SiC}, \mathrm{Al}_{2} \mathrm{O}_{3}$, and Garnet abrasive. The workpiece and abrasive material parameters are shown in Table 1.

To be able to observe the cutting effect of abrasive particles on the workpiece surface, the numerical 
Table 1. Workpiece and abrasive material parameters

\begin{tabular}{lccc}
\hline Material & $\begin{array}{c}\text { Density } \\
{\left[\mathrm{kg} / \mathrm{m}^{3}\right]}\end{array}$ & $\begin{array}{c}\text { Modulus of } \\
\text { elasticity [GPa] }\end{array}$ & $\begin{array}{c}\text { Poisson's } \\
\text { ratio }\end{array}$ \\
\hline Stainless steel & 7930 & 200 & 0.247 \\
\hline $\mathrm{SiC}$ & 2975 & 322 & 0.142 \\
\hline $\mathrm{Al}_{2} \mathrm{O}_{3}$ & 3965 & 305 & 0.24 \\
\hline Abrasive garnet & 4000 & 248 & 0.27 \\
\hline
\end{tabular}

simulation was carried out by the impact of different materials on the same workpiece. The equivalent plastic strain cloud diagram of the abrasive particles of different materials on the workpiece is shown in Fig. 1.

As can be found in Fig. 1, the equivalent plastic strain of $\mathrm{SiC}$ is greater than the equivalent plastic strain of $\mathrm{Al}_{2} \mathrm{O}_{3}$ and garnet. Because $\mathrm{SiC}$ abrasive grains have the largest microhardness, $\mathrm{SiC}$ has the largest plastic deformation ability on the surface of the workpiece, the workpiece has the largest cutting force, and the polishing effect on the workpiece is the best. Therefore, $\mathrm{SiC}$ is the best abrasive grain. The abrasive particles used in this study are silicon carbide abrasive particles.

\subsection{Study on Material Removal Mechanism of Single Abrasive Particles to Round the Workpiece}

Abrasive flow precision machining can effectively round the corners, and the angularity of the variablediameter pipe parts will affect the performance of the workpiece directly. Abrasive flow precision

a)

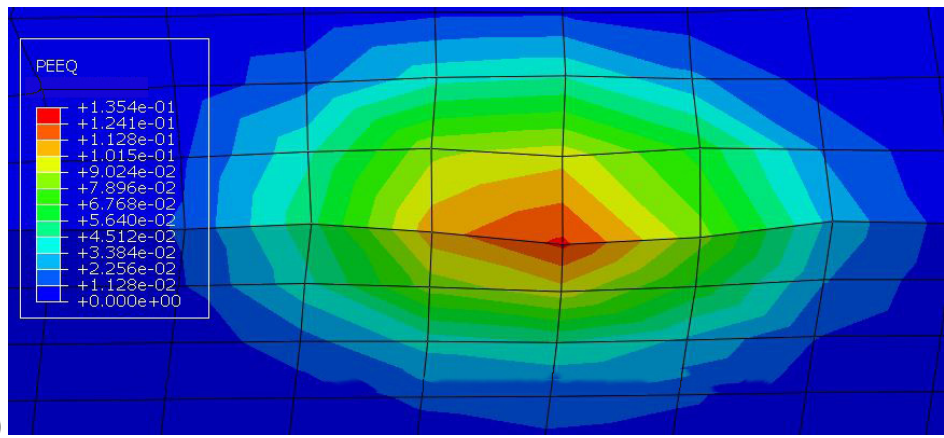

b)
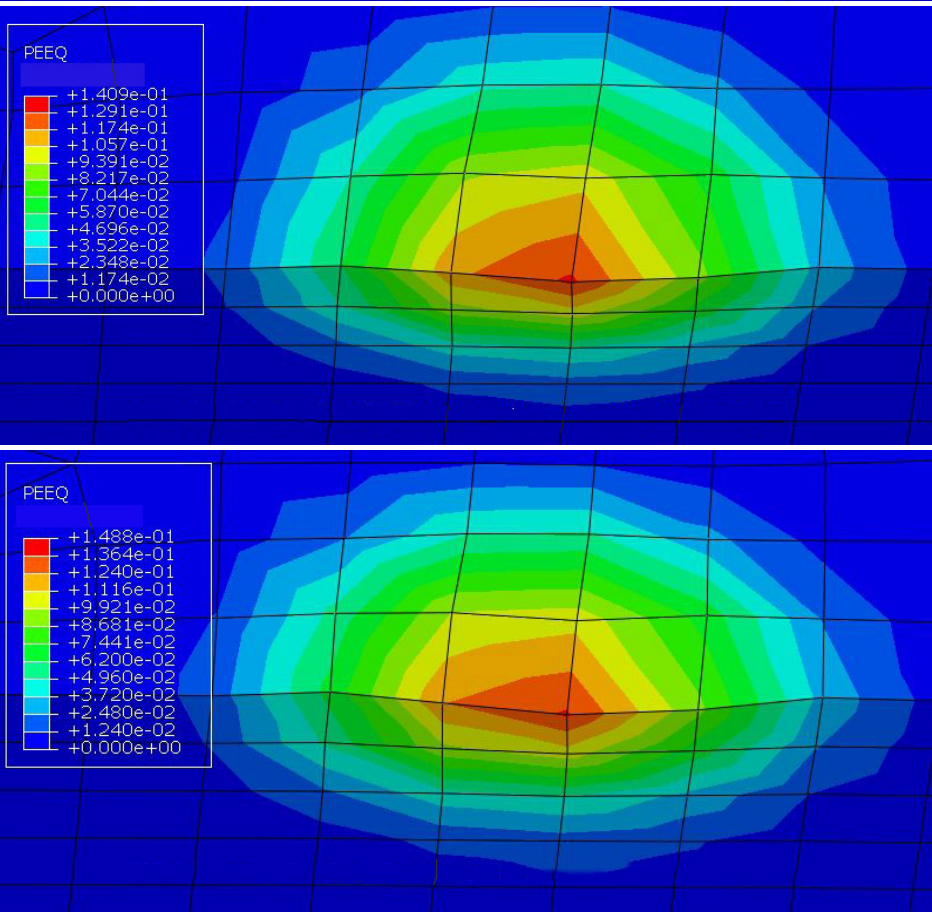

Fig. 1. Equivalent plastic strain cloud diagram of abrasive material of different materials on the target material;

a) equivalent plastic strain cloud diagram of SiC abrasive particles on workpiece, b) equivalent plastic strain cloud diagram of $\mathrm{Al}_{2} \mathrm{O}_{3}$ abrasive particles on workpiece, and c) equivalent plastic strain cloud diagram of abrasive garnet particles on workpiece 
machining can make the angularity of the workpiece smooth, improve the service life of the parts, improve the stability of the whole component, improve the working efficiency, and the rounding of the inner cavity of the abrasive flow has important application value.

To visually observe the effect of the abrasive particles on the workpiece rounding, according to the actual conditions of the abrasive flow precision machining, the incident velocity of the abrasive particle is set at $30 \mathrm{~m} / \mathrm{s}$, and the numerical analysis of abrasive flow precision machining collision is carried out at different incident angles. The total time of the numerical analysis is $8 \times 10^{-5} \mathrm{~s}$. The movement and velocity changes of the abrasive particle collision workpiece wall are shown in Figs. 2 to 5.

It can be seen from the analysis of Figs. 2 to 5 that after the abrasive particles collide with the wall surface, they rebound in a certain direction, and the speed of the abrasive particle decreases. Because a)

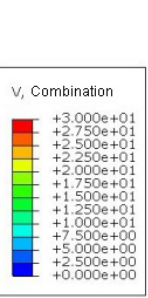

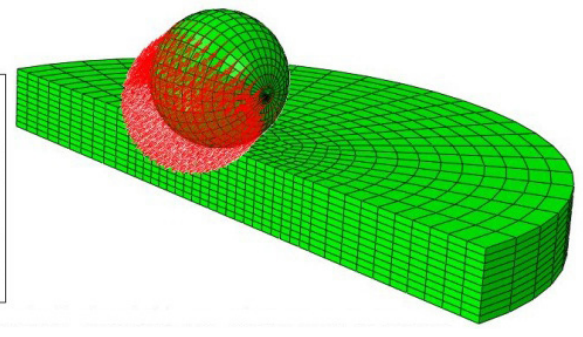

Fig. 2. Spatial velocity nephograms of the abrasive particle rounded off the workpiece at an incident angle of $30^{\circ}$;
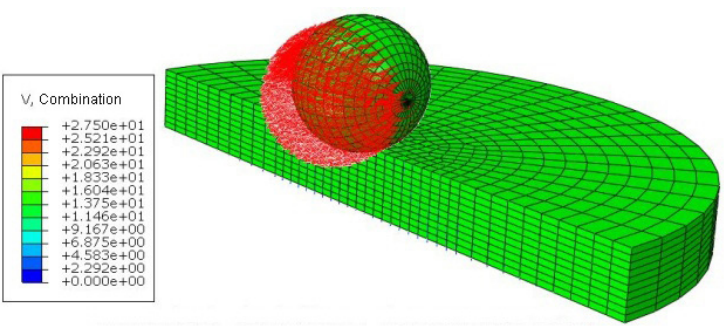

a) $t=0$, and $b) t=2 \times 10^{-5} \mathrm{~s}$

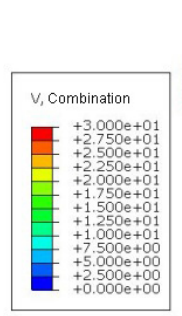

a)

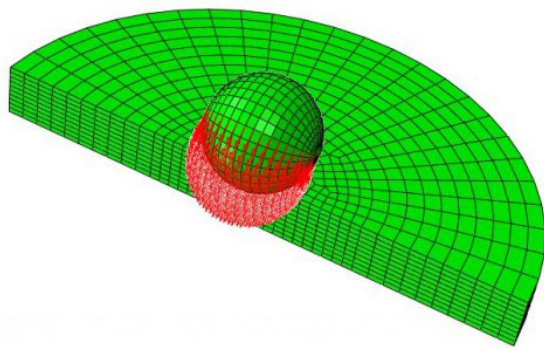

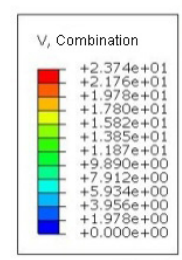

b)

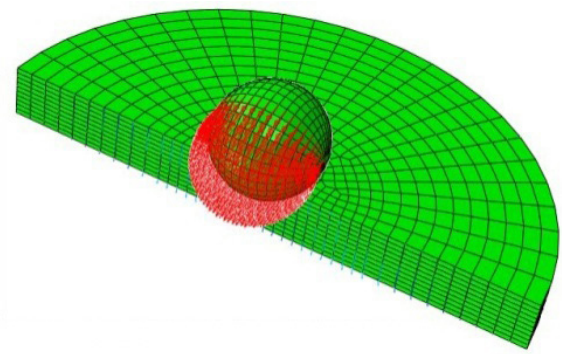

Fig. 3. Spatial velocity nephograms of the abrasive particle rounded off the workpiece at an incident angle of $45^{\circ}$; a) $t=0$, and b) $t=2 \times 10^{-5} \mathrm{~s}$
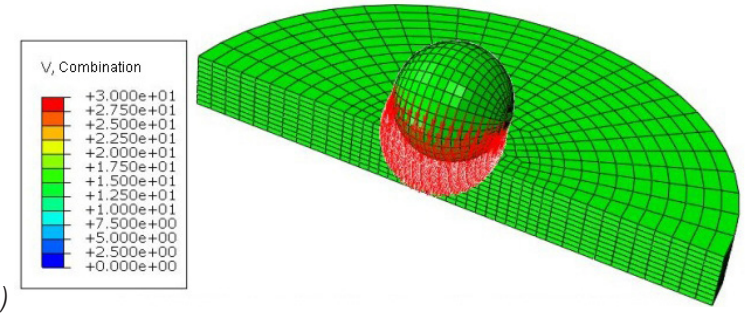

b)

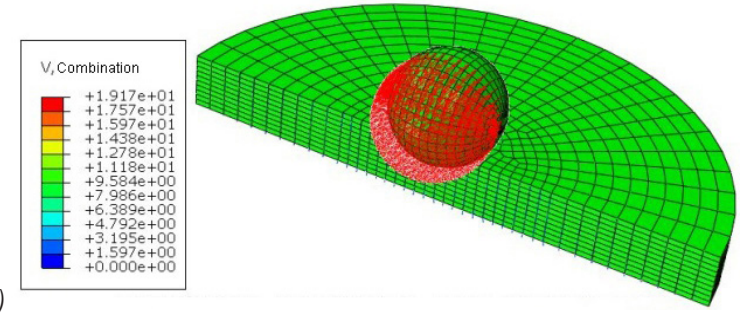

Fig. 4. Spatial velocity nephograms of the abrasive particle rounded off the workpiece at an incident angle of $60^{\circ}$; a) $t=0$, and b) $t=2 \times 10^{-5} \mathrm{~s}$

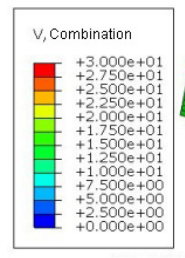

a)

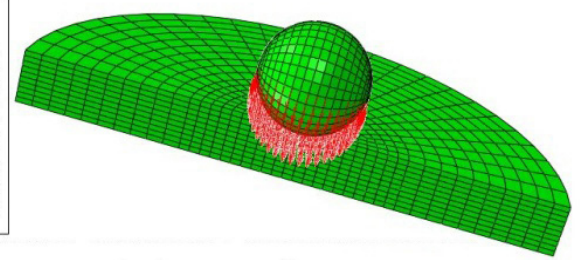

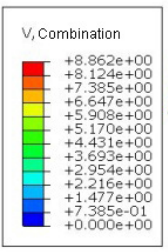

b)

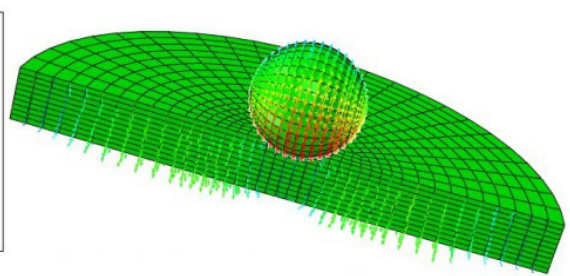

Fig. 5. Spatial velocity nephograms of the abrasive particle rounded off the workpiece at an incident angle of $90^{\circ}$;

a) $t=0$, and b) $t=2 \times 10^{-5} \mathrm{~s}$ 

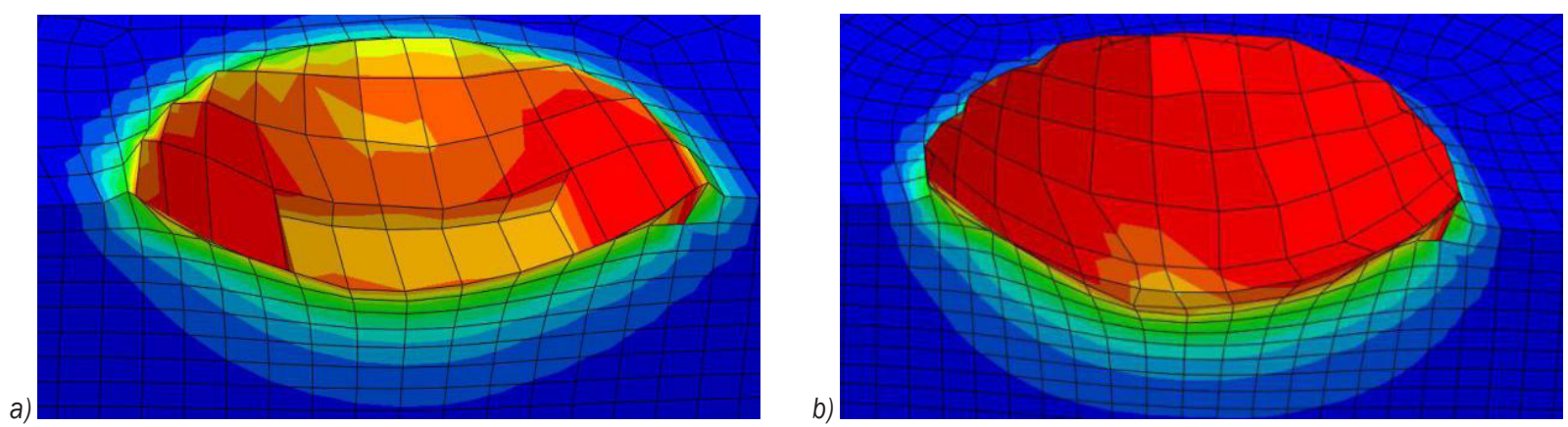

Fig. 6. Material failure and plastic deformation at different incident angles during the fifth collision;

a) when the incident angle is $45^{\circ}$, and b) when the incident angle is $90^{\circ}$

when the workpiece is rounded, the kinetic energy of the abrasive particle is transformed into the internal energy required for the deformation of the workpiece, so that the workpiece is plastically deformed; when the abrasive particles rebound, their velocity starts to increase again, because the reversible plastic deformation begins to recover, which produces reaction force on the abrasive particle and increases the velocity of the abrasive particle; the larger the incident angle, the more the kinetic energy of the abrasive particle is decreased, and the greater the plastic strain of the workpiece. After a plurality of collisions of the abrasive particle on the workpiece, the surface material of the workpiece is removed, thereby forming a rounding effect on the workpiece.

To study the material removal effect of the abrasive particles on the workpiece at different incident angles, five identical abrasive particles were selected to collide on the same position of the workpiece, and $45^{\circ}$ and $90^{\circ}$ were selected for numerical simulation analysis. The material failure and plastic deformation at different incident angles during the fifth collision are shown in Fig. 6.

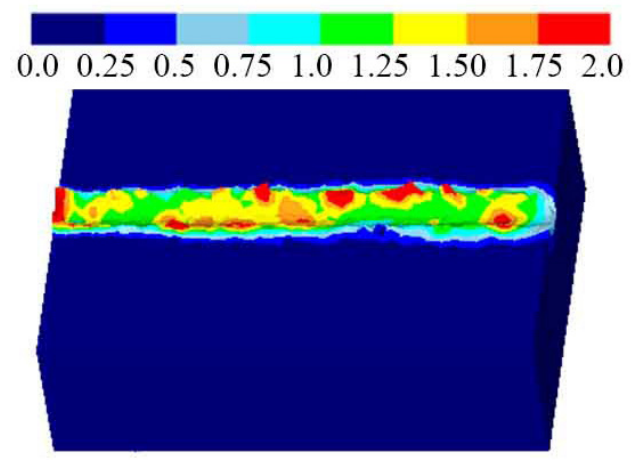

Fig. 7. Equivalent effective strain diagram of a single abrasive particle on wall surface sliding friction
It can be seen from Fig. 6 that the plastic strain is not obvious when the incident angle is $45^{\circ}$, but the impact of the abrasive particles has already caused material removal on the workpiece. The part of the workpiece surface removed is the maximum force of the abrasive particles on the workpiece wall. The part is also the angular part of the workpiece, which in turn forms the rounding effect of the abrasive particles on the workpiece. When the incident angle is $90^{\circ}$, the plastic strain of the workpiece is obvious. The groove after the impact of the abrasive particles is deeper than the incident angle of $45^{\circ}$, but the material is not removed from the workpiece.

\subsection{Study on Material Removal Mechanism of Single Abrasive Particle on Wall Surface Sliding}

To better reveal the material removal mechanism of the abrasive particle collision on the wall surface, numerical analysis of the workpiece and the abrasive particle was carried out. The workpiece wall target was set as a cuboid, the size of the target was 1000 $\mu \mathrm{m} \times 500 \mu \mathrm{m} \times 100 \mu \mathrm{m}$, the diameter of the abrasive particle was 300 meshes, the incident velocity of the abrasive particle was $30 \mathrm{~m} / \mathrm{s}$, and there was slight contact between the abrasive particle and the workpiece wall surface when the abrasive particle

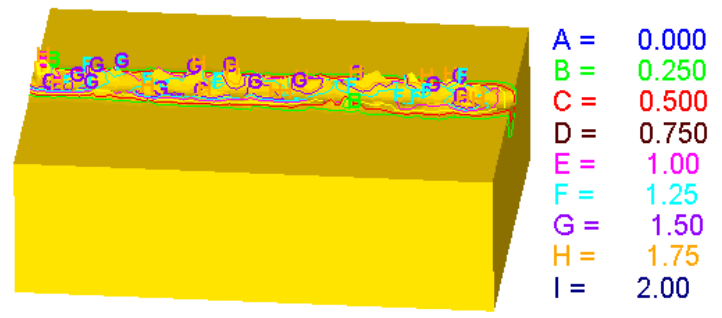

Fig. 8. Equivalent effective strain contour map of a single abrasive particle on wall surface sliding friction 
collided with the workpiece wall surface. The equivalent effective strain and equivalent effective strain contour maps of the single abrasive particle to wall surface sliding friction are obtained via numerical simulation of abrasive flow precision machining, as shown in Figs. 7 and 8.

From Fig. 7, it can be seen that in the process of solid-liquid two-phase abrasive flow precision machining, the abrasive particles are subjected to multiple random collisions on the surface of the workpiece under the action of fluid turbulence, and the normal load presses the abrasive particles into the surface of the workpiece. The tangential movement of abrasive particles causes relative sliding between the abrasive particles and the workpiece surface, causing plastic deformation on the surface of the workpiece, causing a scratch on the workpiece, causing plastic wear on the surface of the workpiece. After a number of the abrasive particles micro-slide on the surface of the workpiece, the final realization of the workpiece surface material is removal and finishing. It can be seen from Fig. 8 that the position of the abrasive particles extrusion on the workpiece is different, as is the amount of plastic deformation. This is because the force of the abrasive particles on the surface of the workpiece is different, and the location where the abrasive particles force on the workpiece is larger, the amount of plastic deformation is larger, the amount of wear on the workpiece is larger, the cutting ability is stronger, and the material removal ability is stronger.

\section{RESULTS AND DISCUSSION}

\subsection{Numerical Analysis and Discussion on Precision Machining of Solid-liquid Two-phase Abrasive Flow}

The research workpiece is a coaxial $5^{\text {th }}$ order variablediameter pipe with symmetrical rotary structure features. The total length of the pipe is $12.7 \mathrm{~mm} \pm 0.05$ $\mathrm{mm}$, and the diameter is $3.17 \mathrm{~mm}$. The numerical analysis of the solid-liquid two-phase abrasive flow precision machining is based on the coupling of CFDDEM to keep abrasive concentration and abrasive particle size unchanged. The polishing performance of abrasive flow is studied and analysed by changing the inlet velocity and incident angle of the abrasive particles. CFD-DEM coupling requires a high quality of the flow channel model mesh. Therefore, the hexahedral mesh is selected to mesh the $5^{\text {th }}$ order variable-diameter pipe, and the flow channel model is divided into blocks according to the geometric shape of the model. After meshing, the $5^{\text {th }}$ order variable diameter pipe forms 490,113 nodes. In this paper, the common index detection of unstructured grid quality is carried out, and there is no negative volume, which indicates that the grid quality is reliable, and the grid quality is greater than 0.3 to meet the simulation requirements. The time step in DEM is set to $5 \mathrm{e}-7$ $\mathrm{s}$ and turns on track collisions. The total time for numerical simulation is $1 \mathrm{~s}$. The two-dimensional model of the $5^{\text {th }}$ order variable-diameter pipe and its flow channel meshing are shown in Fig. 9.

To facilitate the analysis of the numerical variation trend of the $5^{\text {th }}$ order variable-diameter pipe, the $5^{\text {th }}$ order variable-diameter pipe is divided into $1^{\text {st }}$ order region, $2^{\text {nd }}$ order region, $3^{\text {rd }}$ order region, $4^{\text {th }}$ order region and $5^{\text {th }}$ order region. The $1^{\text {st }}$ order region, $2^{\text {nd }}$ order region, $3^{\text {rd }}$ order region, $4^{\text {th }}$ order region and $5^{\text {th }}$ order region are, respectively, set up with $1^{\text {st }}$ order centreline, $2^{\text {nd }}$ order centreline, $3^{\text {rd }}$ order centreline, $4^{\text {th }}$ order centreline and $5^{\text {th }}$ order centreline. The centreline of workpiece rotation is defined as the origin of the centreline of each order region. The centreline of workpiece rotation is positive above and negative below. The abrasive inlet is defined as the origin of the workpiece rotation centreline. The wall

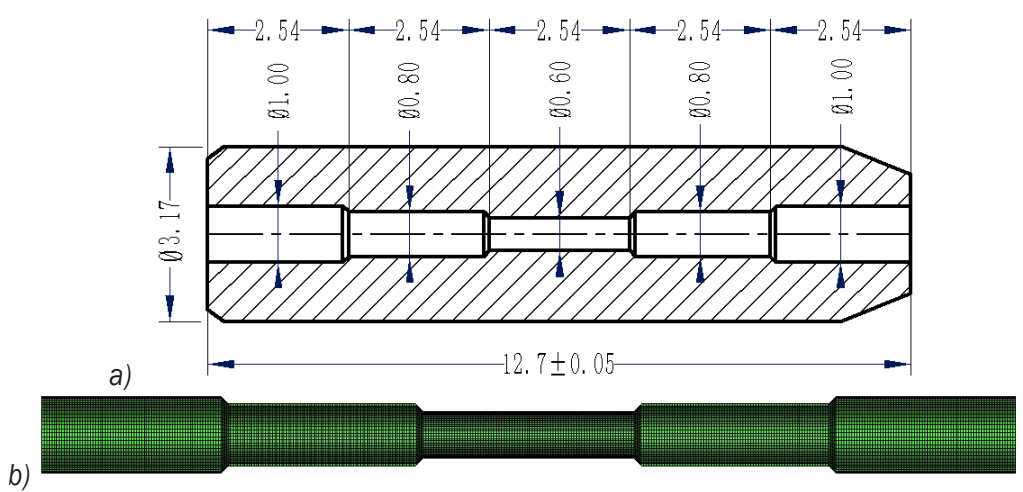

Fig. 9. Two-dimensional model of the $5^{\text {th }}$ order variable-diameter pipe and its flow channel meshing; a) two-dimensional model of the $5^{\text {th }}$ order variable-diameter pipe, and b) the flow channel meshing of the $5^{\text {th }}$ order variable-diameter pipe 
surface in the positive direction of Y-axis is defined as the upper wall surface, while the wall surface in the negative direction of Y-axis is the lower wall surface. The incident angle of abrasive is set to $\alpha$, the regional division of the flow channel of the two-dimensional model of the $5^{\text {th }}$ order variable-diameter pipe is shown in Fig. 10.

\subsubsection{Numerical Simulation Analysis of Precision Machining of Inlet Velocity on $5^{\text {th }}$ order Variable-diameter Pipe}

(1) Coupled field analysis of fluid-dynamic pressure and total energy of abrasive particles in $5^{\text {th }}$ order variable-diameter pipe machined at different inlet velocities. The abrasive concentration was set to $10 \%$, the abrasive particle size was 300 mesh (48 $\mu \mathrm{m})$, and the inlet velocity was $30 \mathrm{~m} / \mathrm{s}$ and $45 \mathrm{~m} / \mathrm{s}$ for CFD-DEM coupling numerical simulation analysis. Cloud dynamic pressure and total particle energy cloud diagrams of CFD-DEM coupling fields at different inlet velocities were obtained, as shown in Fig. 11.

It can be seen from Fig. 11 that the dynamic pressure increases stepwise when the abrasive flow flows from the $1^{\text {st }}$ order region to the $3^{\text {rd }}$ order region. This is because the dynamic pressure is increased by the aperture reduction, the more intense the abrasive movement, and the increased chance of wall surface collision. Thereby, the polishing effect of the abrasive flow on the small aperture can be improved. The $3^{\text {rd }}$ order region has the highest dynamic pressure and the best polishing effect on the $3^{\text {rd }}$ order region. When the abrasive flows from the $3^{\text {rd }}$ order region to the $5^{\text {th }}$ order region, due to the influence of the inertia of abrasive, the dynamic pressure at the intersection of the large hole and the small hole remains relatively high. With the abrasive flowing out, the dynamic pressure decreases gradually. Because of the enlargement of the aperture, the abrasive rarely reaches the workpiece near the wall surface, and the abrasive directly flows out of the workpiece from the fluid centre, so the dynamic pressure near the wall surface is the lowest value, which is not conducive to the finishing of the $4^{\text {th }}$ order region and the $5^{\text {th }}$ order region. To improve the uniformity of abrasive flow precisionmachining workpiece, the workpiece can be processed in two directions.

(2) Coupled field analysis of shear force on the fluid wall of the $5^{\text {th }}$ order variable-diameter pipe machined at different inlet velocities

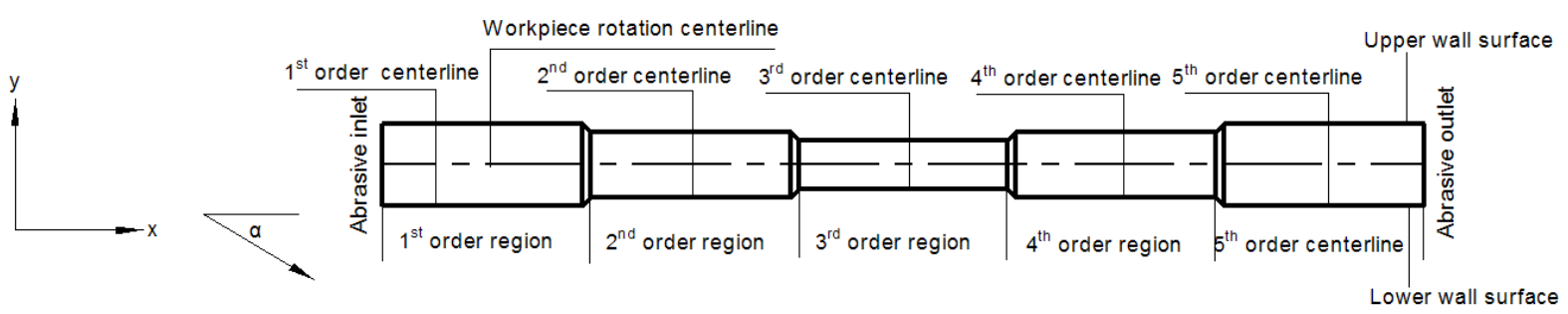

Fig. 10. Schematic diagram of the regional division of the flow channel in the two-dimensional model of the $5^{\text {th }}$ order variable-diameter pipe

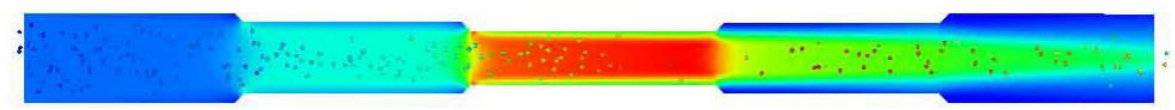

$4.801 e+002 \quad 1.534 e+008 \quad 3.069 e+008 \quad 4.603 e+008 \quad 1.394 e-008 \quad 1.463 e-006 \quad 2.913 e-006 \quad 4.363 e-006$

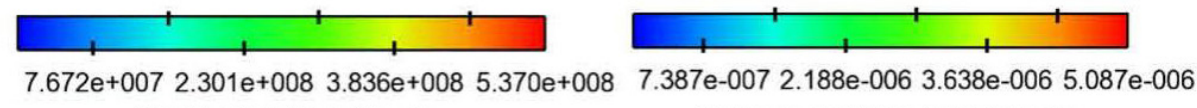

a)

Fluid dynamic pressure

Abrasive particles total energy

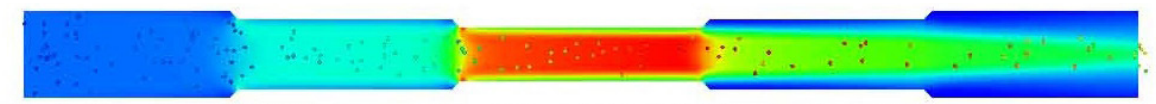

$2.432 e+0033.414 e+0086.828 e+0081.024 e+009 \quad 1.965 e-007 \quad 3.377 e-006 \quad 6.557 e-006 \quad 9.737 e-006$

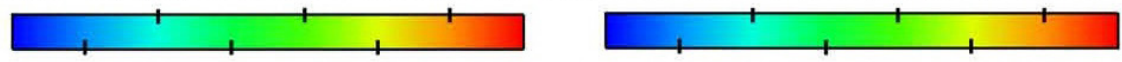

$1.707 e+0085.121 e+0088.535 e+008 \quad 1.195 e+009 \quad 1.787 e-006 \quad 4.967 e-006 \quad 8.147 e-006 \quad 1.133 e-005$

b)

Fluid dynamic pressure Abrasive particles total energy

Fig. 11. Coupled field nephograms of fluid-dynamic pressure and total energy of abrasive particles at different inlet velocities; a) inlet velocity is $30 \mathrm{~m} / \mathrm{s}$, and b) inlet velocity is $45 \mathrm{~m} / \mathrm{s}$ 


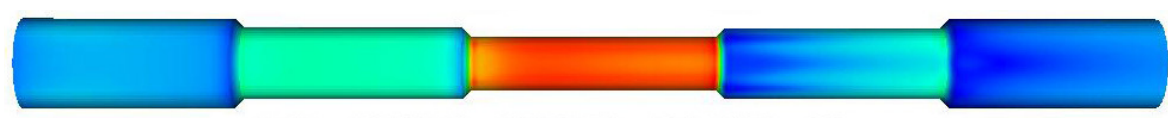

$0.000 e+0007.675 e+0031.535 e+0042.303 e+004$

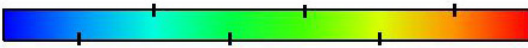

$3.838 e+0031.151 e+0041.919 e+0042.686 e+004$

a)

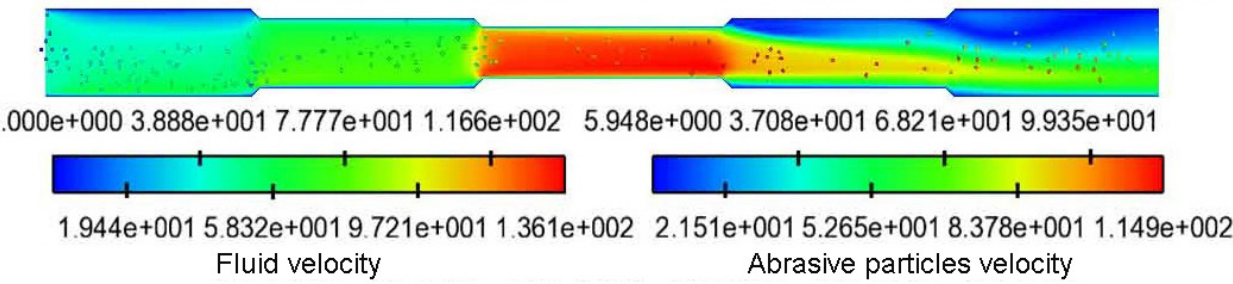

b)

Fig. 12. Coupled field nephograms of fluid wall surface shear force under different inlet velocity conditions; a) when the inlet velocity is $30 \mathrm{~m} / \mathrm{s}$, and b) when the inlet velocity is $45 \mathrm{~m} / \mathrm{s}$

Since the abrasive is a viscous liquid, it has a certain viscous effect on the wall surface, and the abrasive is similar to "adsorption" on the wall surface of the workpiece. When the abrasive particles in the fluid leave the wall surface of the workpiece, it is necessary to overcome the viscous resistance and the adsorption force between the abrasive particles in the fluid and the wall surface of the workpiece. At this time, a certain shear force is formed on the wall surface of the workpiece, and the shear force is greater than the ultimate stress of the workpiece surface material, the workpiece material falls off the surface of the workpiece. Under the same numerical simulation conditions, the coupled field nephograms of fluid wall surface shear force under different inlet velocity conditions is obtained, as shown in Fig. 12.

It can be seen from the colour change of each order region in Fig. 12 that the shear force of the fluid wall surface of the $1^{\text {st }}$ order region to the $3^{\text {rd }}$ order region is gradually increasing. Because the pore diameter is gradually smaller in this process, the pressure of the abrasive on the wall gradually increases, as does the wall shear force. In the $3^{\text {rd }}$ order region, the wall shear force is the largest, and the polishing effect is the best. When the abrasive flows into the $5^{\text {th }}$ order region from the $3^{\text {rd }}$ order region, the wall surface shear force decreases stepwise, because the aperture becomes larger, the pressure of the abrasive flow to the wall surface decreases, and in the $4^{\text {th }}$ order region, the wall surface shear force near the $3^{\text {rd }}$ order region is relatively small, and the middle and rear end wall surface shear force tends to increase, which is beneficial to the finishing of the middle and rear end in the $4^{\text {th }}$ order region, and the polishing effect on the beginning of the $4^{\text {th }}$ order region and the $5^{\text {th }}$ order region is poor.

\subsubsection{Numerical Simulation Analysis of Precision Machining of $5^{\text {th }}$ order Variable-diameter Pipe by Incident Angle}

Since the above processing technology is not conducive to the polishing uniformity of each step of the $5^{\text {th }}$ order variable-diameter pipe, in order to improve the polishing effect of each step of the workpiece, the abrasive flow precision machining for the workpiece at different incident angles is proposed, and the direction of the incident angle of the abrasive is defined as shown in Fig. 10.

(1) Coupled Field Analysis of Fluid Velocity and Abrasive Particles Velocity of $5^{\text {th }}$ order Variablediameter Pipe Machined at Different Incident Angles

When the abrasive concentration is $10 \%$, the abrasive particle size is 300 meshes $(48 \mu \mathrm{m})$ and the inlet velocity is $45 \mathrm{~m} / \mathrm{s}$, the incident angles were selected as $0^{\circ}$ and $15^{\circ}$ for coupled numerical simulation analysis. The fluid velocity and the abrasive particles velocity nephograms for the different incident angles at the coupled field are shown in Fig. 13.

It can be seen from Fig. 13 that the fluid velocity distribution changes when the incident angle is changed; the larger the incident angle is, the more obviously the fluid velocity distribution changes. When the incident angle is $0^{\circ}$, the fluid velocity distribution is symmetric about the workpiece rotation centreline, but when the incident angle is greater than $0^{\circ}$, the fluid velocity is no longer symmetrical about the centreline of the workpiece rotation, and the fluid velocity at the lower end 


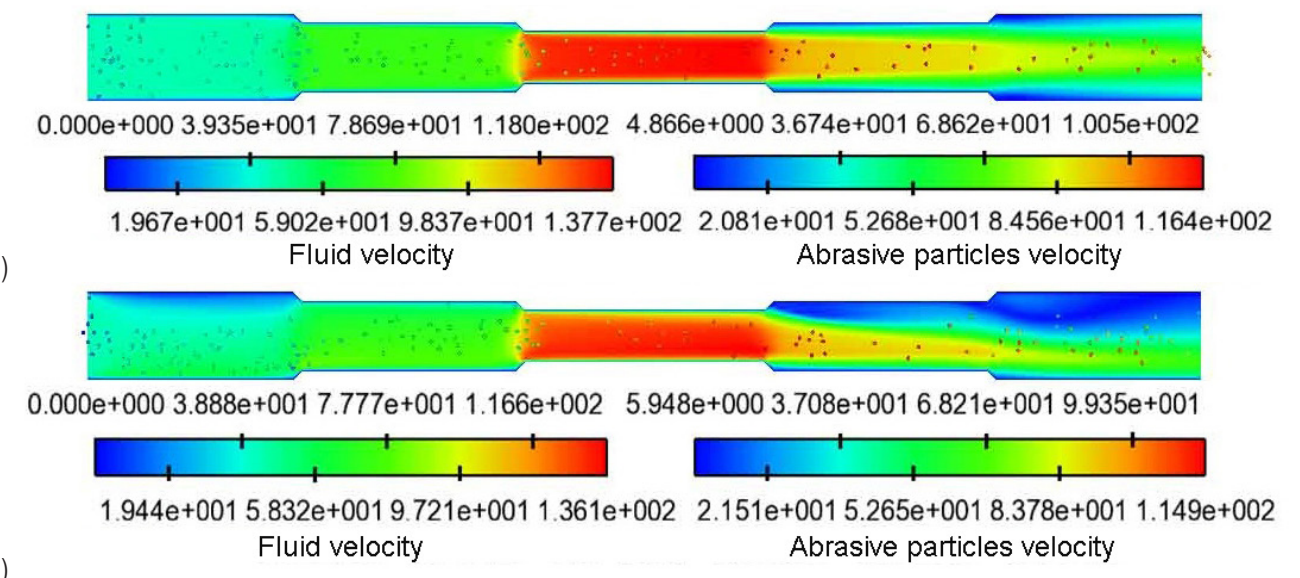

Fig. 13. Coupled field nephograms of fluid velocity and abrasive particle velocity at different incident angles; a) when the incident angle is $0^{\circ}$, and b) when the incident angle is $15^{\circ}$
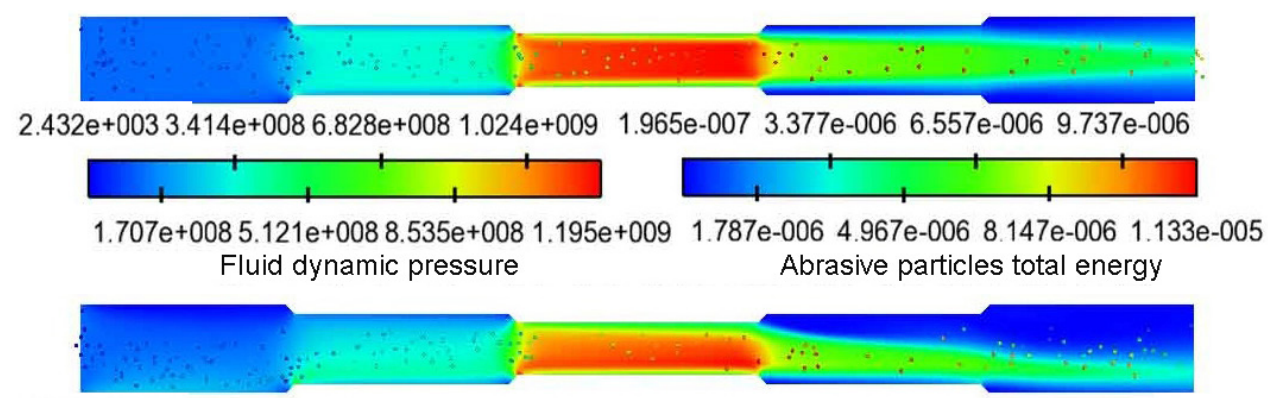

$1.066 e+0033.367 e+0086.733 e+0081.010 e+009 \quad 1.136 e-007 \quad 3.252 e-006 \quad 6.390 e-006 \quad 9.528 e-006$

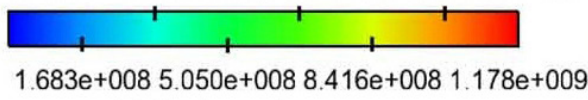

Fluid dynamic pressure

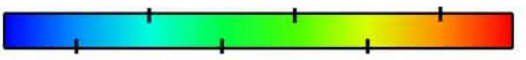

$1.683 \mathrm{e}-006 \quad 4.821 \mathrm{e}-006 \quad 7.959 \mathrm{e}-006 \quad 1.110 \mathrm{e}-005$ Abrasive particles total energy

b)

Fig. 14. Coupled field nephograms of fluid-dynamic pressure and total energy of abrasive particles at different incident angles; a) when the incident angle is $0^{\circ}$, and b) when the incident angle is $15^{\circ}$

of the centreline of the workpiece is greater than that at the upper end, but the fluid velocity near the wall surface of the lower end of the centreline of the workpiece in the $4^{\text {th }}$ order region and $5^{\text {th }}$ order regions is significantly improved. The polishing effect of the lower end wall surface of the workpiece rotation centreline is better than that of the upper end wall surface. Similarly, the $3^{\text {rd }}$ order region has the greatest fluid velocity and uniform fluid velocity distribution, so the polishing effect is best for the $3^{\text {rd }}$ order region. The larger the incident angle is, the more times the abrasive particles collide with the workpiece wall surface, so that the polishing effect of the lower wall surface of the $4^{\text {th }}$ order region and the $5^{\text {th }}$ order region can be improved to some extent.

(2) Coupled field analysis of the fluid-dynamic pressure and total energy of abrasive particles of $5^{\text {th }}$ order variable-diameter pipe machined at different incident angles

Under the same numerical simulation conditions, the coupled field nephograms of fluid-dynamic pressure and total energy of abrasive particles at different incident angles are obtained, as shown in Fig. 14.

It can be seen from Fig. 14 that when the incident angle is $0^{\circ}$, the fluid dynamic pressure distribution is symmetric about the workpiece rotation centreline, and when the incident angle is greater than $0^{\circ}$, the fluid-dynamic pressure is no longer symmetric about the workpiece rotation centreline, but the fluid-dynamic pressure near the lower wall of the $4^{\text {th }}$ order region and the $5^{\text {th }}$ order region is improved. The polishing effect of the lower end wall surface of the workpiece rotation centreline is better than that of the upper end wall 
surface, and the upper wall surface polishing effect is worse. Similarly, the dynamic pressure of the $3^{\text {rd }}$ order region is the largest, and the fluid dynamic pressure distribution is relatively uniform, so the polishing effect is best for the $3^{\text {rd }}$ order region. The total energy of the abrasive particles increases first and then decreases. The total energy of the abrasive particles reaches the maximum at the junction of the $3^{\text {rd }}$ order region and the $4^{\text {th }}$ order region, and the larger the incident angle, the more the number of collisions between the abrasive particles and the lower wall surface of the workpiece, thus, the polishing effect of the lower wall surface of the $4^{\text {th }}$ order region and the

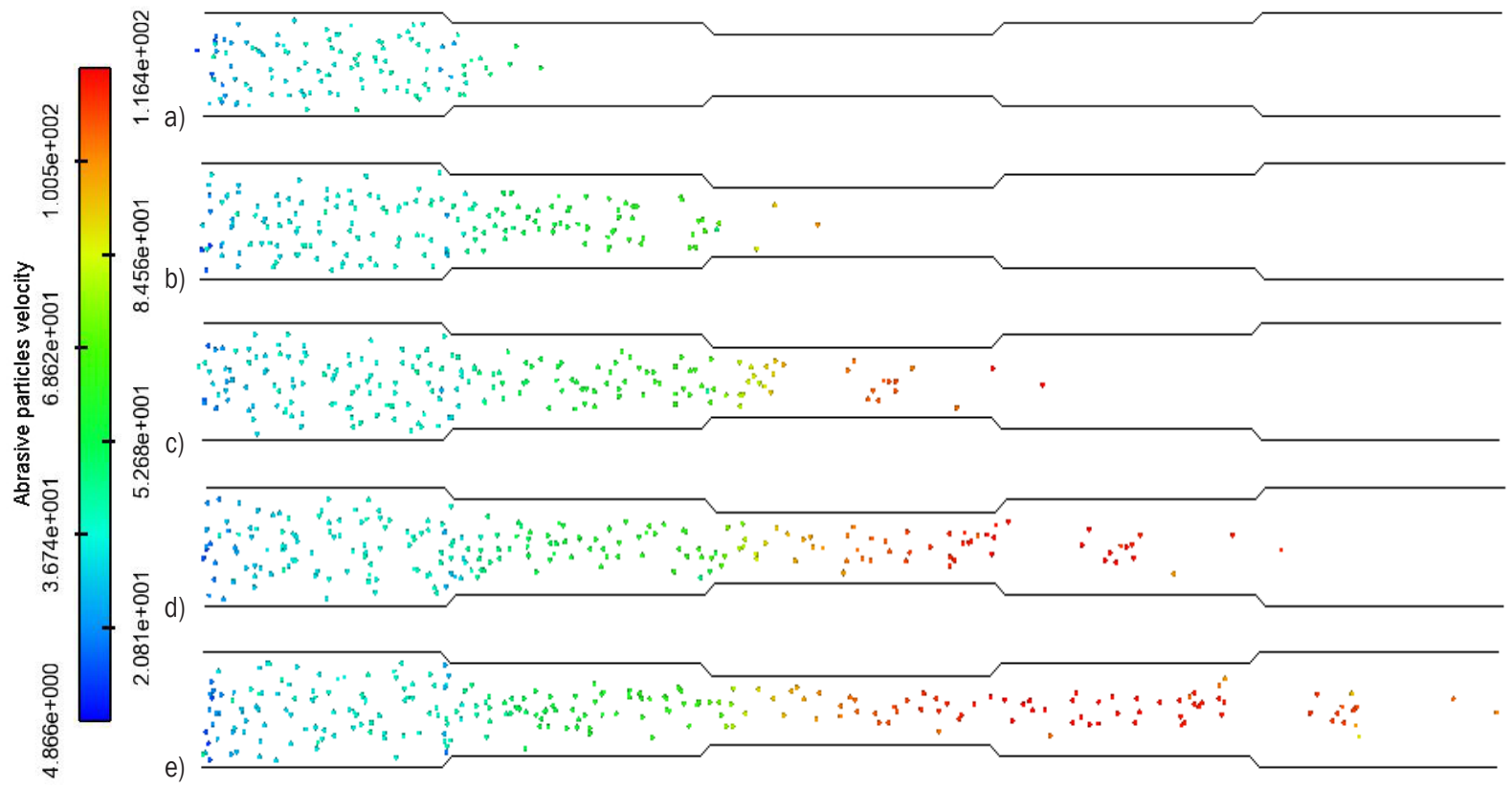

Fig. 15. The movement of the abrasive particles in the fifth-order variable-diameter when the incident angle is $0^{\circ}$; when machining time is a) $6 \mathrm{e}-5 \mathrm{~s}$, b) $1.1 \mathrm{e}-4 \mathrm{~s}, \mathrm{c}) 1.4 \mathrm{e}-4 \mathrm{~s}, \mathrm{~d}) 1.6 \mathrm{e}-4 \mathrm{~s}$, and e) $1.7 \mathrm{e}-4 \mathrm{~s}$

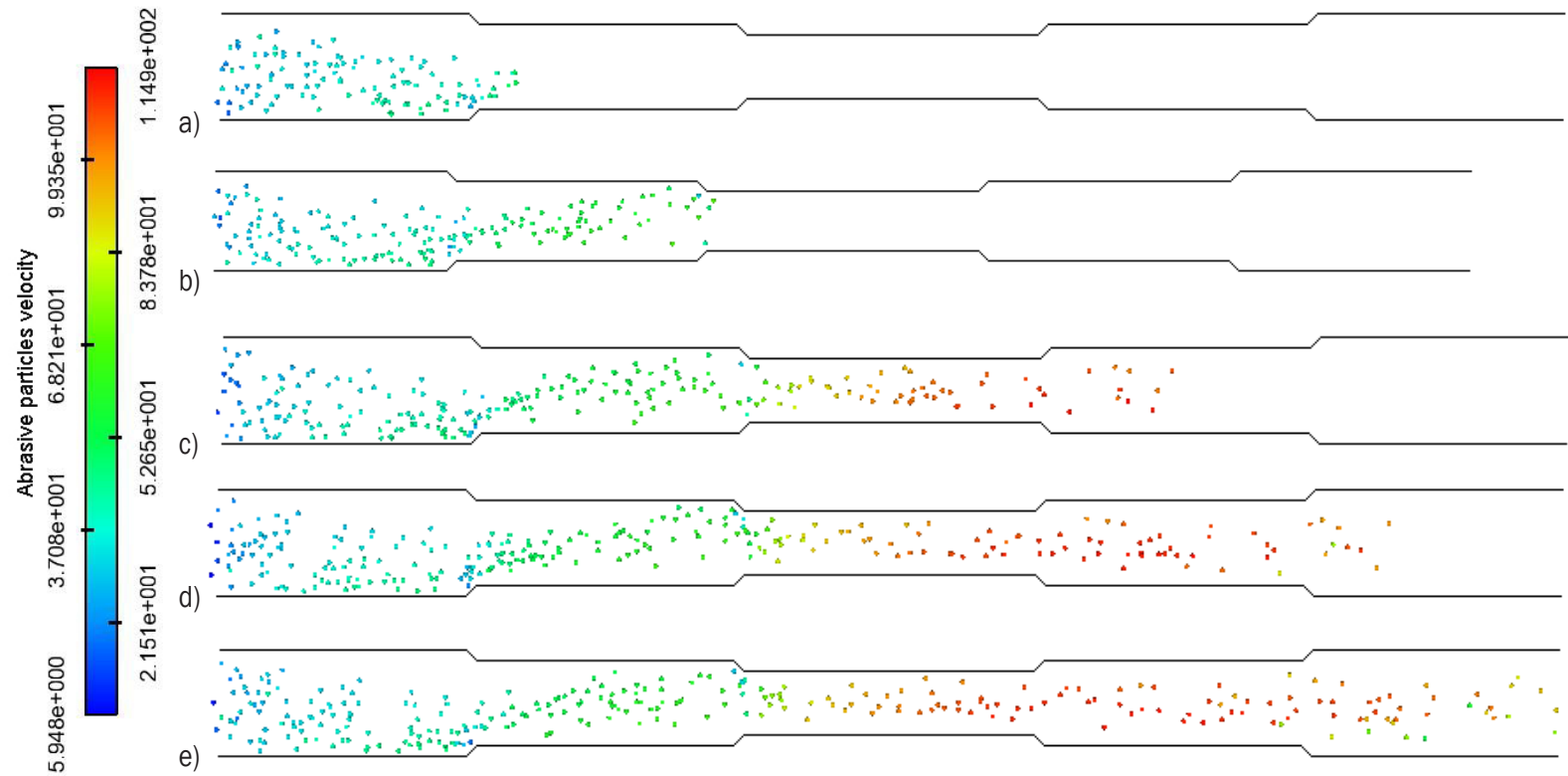

Fig. 16. The movement of the abrasive particles in the fifth-order variable-diameter when the incident angle is $15^{\circ}$; when machining time is a) $6 \mathrm{e}-5 \mathrm{~s}$, b) $1.2 \mathrm{e}-4 \mathrm{~s}, \mathrm{c}) 1.5 \mathrm{e}-4 \mathrm{~s}, \mathrm{~d}) 1.7 \mathrm{e}-4 \mathrm{~s}$, and e) $1.8 \mathrm{e}-4 \mathrm{~s}$ 
$5^{\text {th }}$ order region is improved to a certain extent, and the polishing effect of upper wall surface is poor.

(3) Distribution of abrasive particles in the $5^{\text {th }}$ order variable-diameter pipe at different times when the incident angle is $0^{\circ}$ and $15^{\circ}$

The movement of the abrasive particles at different times in the $5^{\text {th }}$ order variable-diameter pipe was analysed. The numerical simulation was carried out by selecting the incident angles of $0^{\circ}$ and $15^{\circ}$, and the distribution of the abrasive particles at different times was obtained, as shown in Figs. 15 and 16.

From the comparison of Figs. 15 and 16, it can be seen that the distribution of the abrasive particles when the incident angles are $0^{\circ}$ and $15^{\circ}$, respectively, the time required for the abrasive particles to flow out of the workpiece when the incident angle is $0^{\circ}$ is less than that when the incident angle is $15^{\circ}$. It means that the abrasive particles collide with the wall surface for a long time when the incident angle is $15^{\circ}$, which is beneficial to the polishing of the workpiece. When the incident angle is $0^{\circ}$, the distribution of the abrasive particles is uniform. When the incident angle is $15^{\circ}$, the distribution of the abrasive particles is not uniform, and it is concluded that the polishing is uniform when the incident angle is $0^{\circ}$.

\subsection{Test Analysis and Discussion on abrasive Flow Precision Machining of 5th Order Variable-Diameter Pipe}

Many scholars have researched new methods to improve the surface quality of the workpieces being processed. Lopez et al. [28] proposed the use of newly developed utility programmes in the preparation stage for the processing of advanced high-strength steel (AHSS) forming tools, and the use of CAM software to write computer navigated control (CNC) programmes to improve the finishing. Zou et al. [29] verified the feasibility of a flexible grinding method for the precision machining of TiAl-based alloys from the aspects of material removal rate, abrasive wear, surface roughness and residual stress. Gou et al. [30] and other scholars used a UV-curing resin plate grinding process to improve the surface roughness of the workpiece by $12 \%$ and reduce the material removal rate by $25 \%$. Wang et al. [31] developed a new atomic force microscope and studied the effects of abrasive media and process parameters on new abrasive particle flow processing. Wei [32] proposed a new abrasive particle flow machining material removal prediction model, which can predict material removal based on the change of the contour height and the mass change of the material. To verify the effectiveness of abrasive flow polishing variablecalibre pipe parts, the abrasive flow polishing process parameters were selected with an inlet speed of $45 \mathrm{~m} / \mathrm{s}$, an abrasive concentration of $10 \%$, and an abrasive particle size of 800 mesh. Comparative tests of unidirectional and bidirectional abrasive flow polishing were performed.

\subsubsection{Surface Roughness Analysis of Abrasive Flow Precision Machining of $5^{\text {th }}$ order Variable-diameter Pipe}

A $5^{\text {th }}$ order variable-calibre pipe made of stainless steel 304 was selected as the abrasive flow polishing test object. The physical diagram of the $5^{\text {th }}$ order variable-diameter pipe after cutting is shown in Fig. 17.

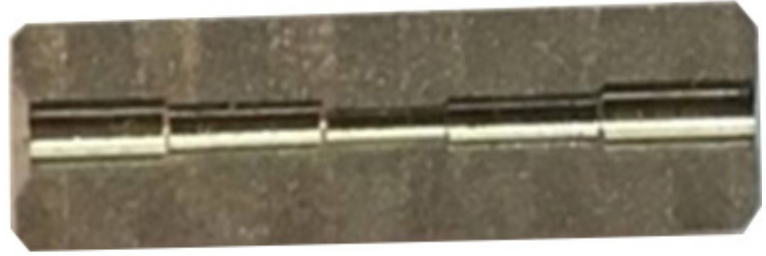

Fig. 17. Physical diagram of the $5^{\text {th }}$ order variable-diameter pipe after cutting

To analyse the internal surface roughness of the workpiece before and after the abrasive flow polishing, a Mahr stylus gauge is selected for surface roughness detection on the inner surface of the $5^{\text {th }}$ order variable calibre tube. The inner surface of the $5^{\text {th }}$ order variable-calibre pipe is contact-tested by a probe. The surface roughness $R a$ value of the $5^{\text {th }}$ order variable-calibre pipe is shown in Table 2.

Table 2. Surface roughness $R$ a values of the $5^{\text {th }}$ order variablediameter pipe before and after one-way and two-way abrasive flow precision machining

\begin{tabular}{lccc}
\hline \multirow{2}{*}{ Region } & \multicolumn{3}{c}{ Surface roughness Ra value $[\mu \mathrm{m}]$} \\
\cline { 2 - 4 } & Original & $\begin{array}{c}\text { After one-way } \\
\text { machining }\end{array}$ & $\begin{array}{c}\text { After two-way } \\
\text { machining }\end{array}$ \\
\hline 1st order region & 1.422 & 0.430 & 0.329 \\
\hline $2^{\text {nd }}$ order region & 1.413 & 0.306 & 0.279 \\
\hline $3^{\text {rd }}$ order region & 1.476 & 0.257 & 0.218 \\
\hline $4^{\text {th }}$ order region & 1.465 & 0.571 & 0.294 \\
\hline $5^{\text {th }}$ order region & 1.458 & 0.710 & 0.367 \\
\hline
\end{tabular}

It can be seen from Table 2 that the surface roughness after one-way and two-way abrasive flow precision machining is significantly reduced, and the surface quality of the workpiece is improved. Through 
the comparison and analysis of each order region of one-way abrasive flow precision machining, the inner surface roughness value is $5^{\text {th }}$ order region $>4^{\text {th }}$ order region $>1^{\text {nd }}$ order region $>2^{\text {st }}$ order region $>3^{\text {rd }}$ order region. This shows that the size of the aperture will affect the inner surface roughness value. The smaller the aperture, the larger the amount of material removed, and the better the polishing effect on the workpiece, but the polishing of each order region is uneven, and the two-way abrasive flow precision machining improves the unevenness of polishing. To visually observe the trend of the original, one-way and two-way surface roughness values, a surface roughness line chart of each order region, as shown in Fig. 18, is drawn.

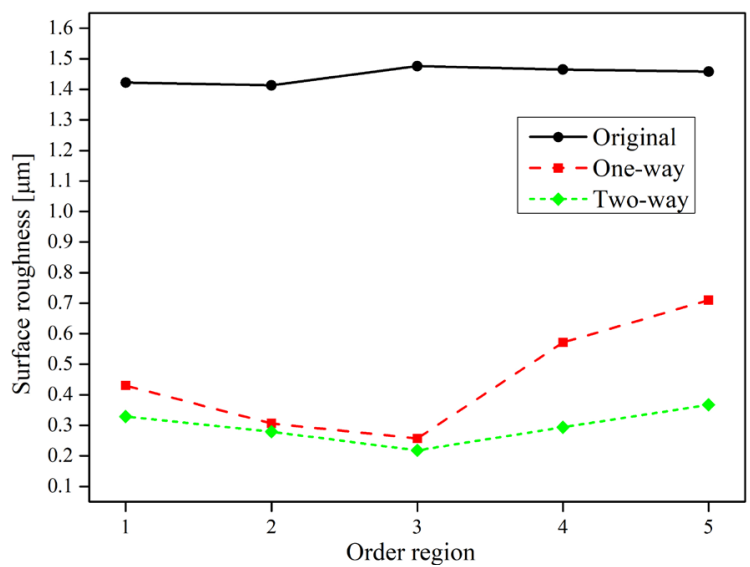

Fig. 18. Surface roughness line chart of each order region before and after abrasive flow precision machining
From Fig. 18, it can be seen that the surface roughness of each order region after one-way and twoway abrasive flow precision machining is reduced. The surface roughness of the $4^{\text {th }}$ order region and the $5^{\text {th }}$ order region after one-way abrasive flow precision machining was larger, and the polishing effect is not good. The inner surface roughness value of each order region after two-way abrasive flow precision machining is relatively flat, which is beneficial to improve the inner surface quality of the workpiece.

\subsubsection{Surface Morphology Analysis of Abrasive Flow Precision Machining of $5^{\text {th }}$ order Variable-diameter Pipe}

To better analyse the surface quality of abrasive flow precision machining the $5^{\text {th }}$ order variablediameter pipe, scanning electron microscopy (SEM) is used to detect the surface morphology of the $5^{\text {th }}$ order variable-diameter pipe before and after oneway abrasive flow precision machining. The surface morphology of the $5^{\text {th }}$ order variable-diameter pipe before and after abrasive flow precision machining is obtained, as shown in Figs. 19 and 20.

It can be determined from Figs. 19 and 20 that a large number of uneven spots and burrs are distributed on the inner surface of the $5^{\text {th }}$ order variable-aperture pipe workpiece before the abrasive flow polishing, the distribution is relatively disordered, and the surface quality is poor. After polishing with a unidirectional abrasive flow, many striped scratches appeared on the surface of the workpiece, and the spots and burrs
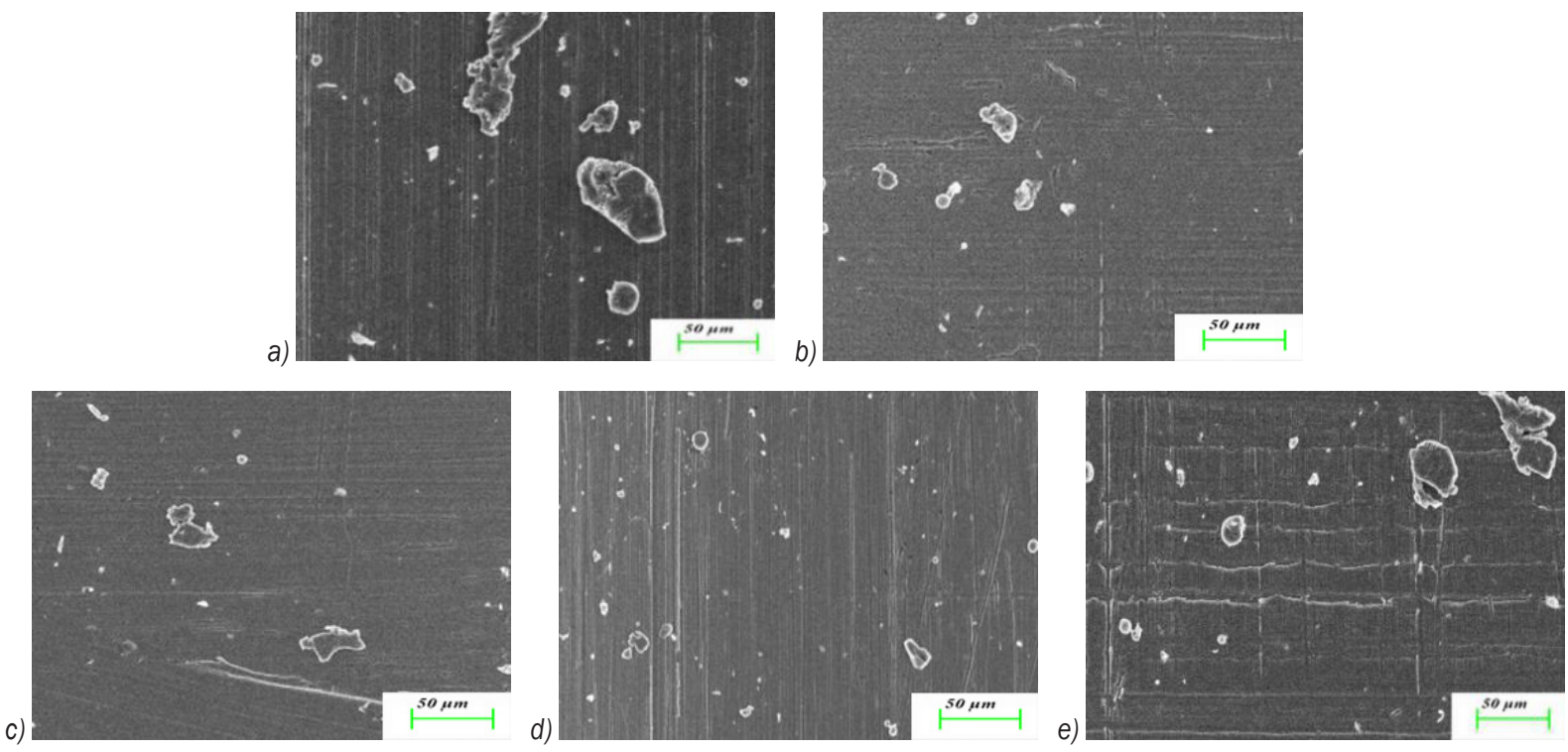

Fig. 19. Surface morphology of the $5^{\text {th }}$ order variable-diameter pipe before abrasive flow precision machining; a) $1^{\text {st }}$ order region, b) $2^{\text {nd }}$ order region, c) $3^{\text {rd }}$ order region, d) $4^{\text {th }}$ order region, and e) $5^{\text {th }}$ order region 
a)

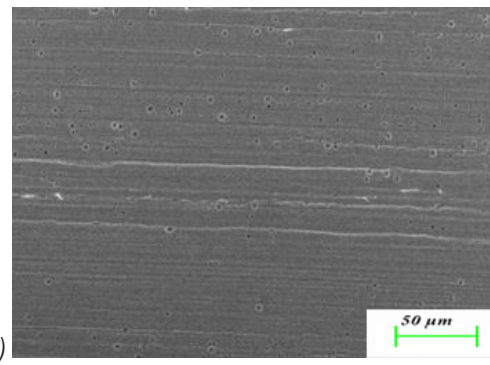

b)

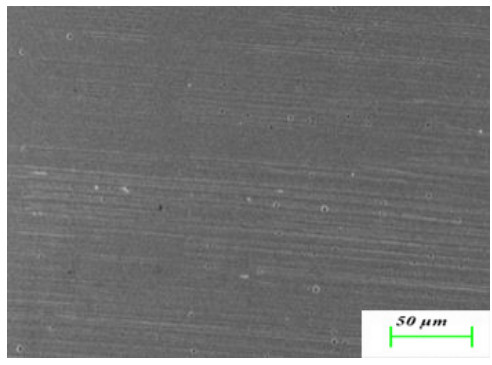

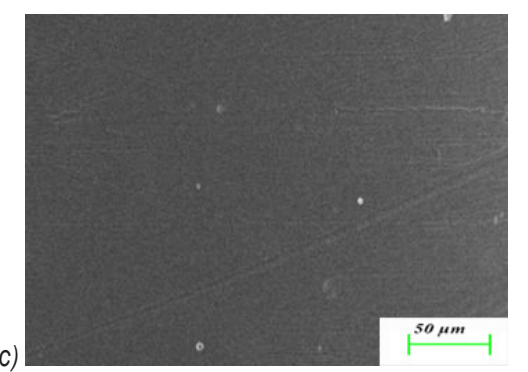
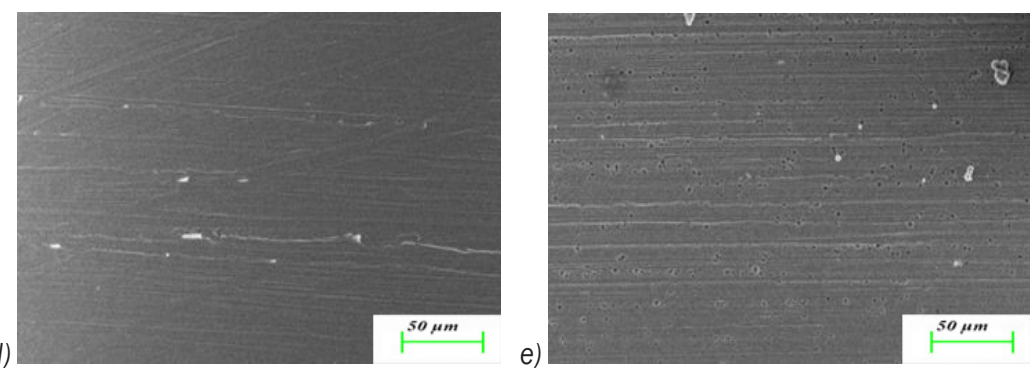

Fig. 20. Surface morphology of the $5^{\text {th }}$ order variable-diameter pipe after one-way abrasive flow precision machining; a) $1^{\text {st }}$ order region, b) $2^{\text {nd }}$ order region, c) $3^{\text {rd }}$ order region, d) $4^{\text {th }}$ order region, and e) $5^{\text {th }}$ order region

on the workpiece surface basically disappeared, the surface was smoother, and the surface quality is significantly improved. A comparative analysis of each step region of the $5^{\text {th }}$ order variable-calibre pipe can be seen: the smoothness of the $1^{\text {st }}$ order region and the $2^{\text {nd }}$ order region is better, and the surface quality is significantly improved. The $3^{\text {rd }}$ order region has the best finish and the best polishing effect. A small amount of glitches are found in the $4^{\text {th }}$ order region, and the surface quality of the $5^{\text {th }}$ order region is the worst. The surface roughness $\mathrm{Ra}$ value of each area of the $5^{\text {th }}$ order variable-calibre tube after precision machining by the abrasive flow is $5^{\text {th }}$ order region $>4^{\text {th }}$ order region $>1^{\text {st }}$ order region $>2^{\text {nd }}$ order region $>3^{\text {rd }}$ order region. The detection results are consistent with the numerical simulation results, which verifies the accuracy of the numerical simulation. By examining the surface morphology after polishing with bidirectional abrasive flow, and the surface morphology diagram shown in Fig. 21 is obtained. a)

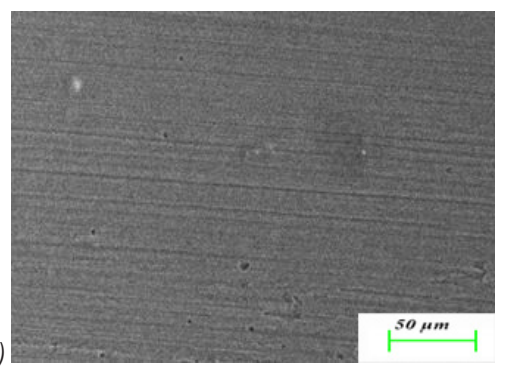

b)
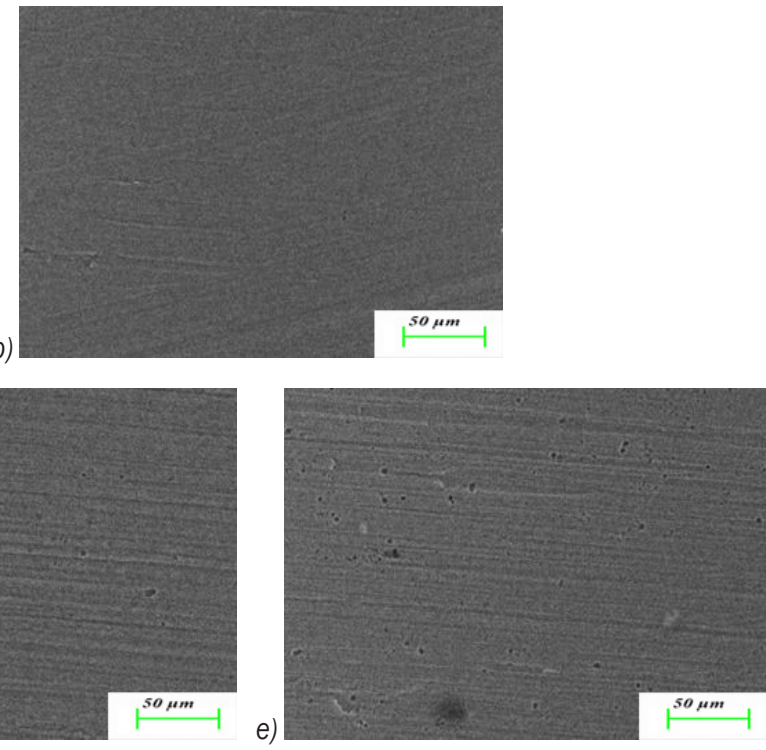

e)

c)
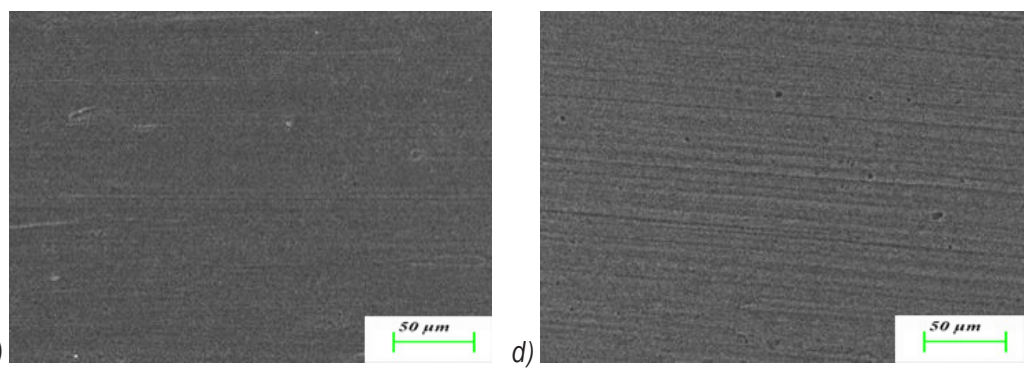

Fig. 21. Surface morphology of the $5^{\text {th }}$ order variable-diameter pipe after two-way abrasive flow precision machining; a) $1^{\text {st }}$ order region, b) $2^{\text {nd }}$ order region, c) $3^{\text {rd }}$ order region, d) $4^{\text {th }}$ order region, and e) $5^{\text {th }}$ order region 
It can be seen from Fig. 21 that the stripe-like scratches on the surface of the $5^{\text {th }}$ order variableaperture pipe are clearer after the bidirectional abrasive flow polishing, the burr on the surface of the workpiece disappears, the surface is smoother, and the surface quality is significantly improved. A comparative analysis of each order region shows that the processing effect of the $1^{\text {st }}$ order region and the $5^{\text {th }}$ order region is close; the surface quality of the $2^{\text {nd }}$ order region and the $4^{\text {th }}$ order region are also very close; the inner surface of the $3^{\text {rd }}$ order region is the smoothest and has the best polishing effect. Compared with the effect of unidirectional abrasive flow polishing, the internal surface quality of each step region after polishing by bidirectional abrasive flow is significantly improved. Therefore, polishing the fivestep variable-calibre pipe parts with bi-directional abrasive flow can make the processing more uniform, which is more conducive to improving the quality of the inner surface of the workpiece.

\section{CONCLUSION}

(1) During the precision machining with solid-liquid two-phase abrasive flow, the surface finishing of the workpiece is formed by the interaction between the abrasive particles and the wall surface. After the abrasive particles collide with the wall surface, the abrasive particles will rebound in a certain direction, and the kinetic energy of the abrasive particles is converted into the internal energy required for the deformation of the workpiece, so that the surface of the workpiece is plastically deformed; the larger the incident angle, the more kinetic energy of abrasive particles loss, the greater the plastic strain of the workpiece; after multiple collisions of the abrasive particles on the workpiece, the normal load presses the abrasive particles into the surface of the workpiece, and the tangential movement of the abrasive particles causes the abrasive particles to slide relative to the surface, causing plastic deformation to occur on the surface of the workpiece, a scratch on the workpiece, plastic wear on the workpiece surface, when the shear force is greater than the ultimate stress of the workpiece surface material, and after several repetitions of micro-sliding friction on the surface of the workpiece, the abrasive particles eventually achieve the material removal and finishing of the workpiece surface.

(2) Through the numerical analysis of the solid-liquid two-phase abrasive flow precision machining, it is found that the dynamic pressure increases when the abrasive particles flow into the small aperture from the large aperture, and the dynamic pressure decreases when the abrasive particles flow into the large aperture from the small aperture; the greater the dynamic pressure is, the more violent the abrasive particles movement is, the more chance the abrasive particles collide with the wall surface; the dynamic pressure data at the rotation centreline of the $5^{\text {th }}$ order variable-diameter pipe is $3^{\text {rd }}$ order region $>4$ th order region $>5^{\text {th }}$ order region $>2^{\text {nd }}$ order region $>11^{\text {st }}$ order region, the finishing effect of the $3^{\text {rd }}$ order region is the best. The wall surface shear force at the centre of the fluid is 0 , and only the shear force is generated at the wall surface. In the $5^{\text {th }}$ order region, the wall surface shear force is the smallest, the number of collisions between the abrasive particles and the $5^{\text {th }}$ order region wall surface is small, the amount of material removal on the workpiece surface is less, and the polishing effect in the $5^{\text {th }}$ order region is the worst.

(3) Changing the incident angle can change the velocity distribution of the abrasive flow. The larger the incident angle, the more obvious the change of the fluid velocity distribution. When the incident angle is $0^{\circ}$, the fluid velocity distribution is symmetric about the centreline of the workpiece rotation, which can effectively improve the polishing effect of the $4^{\text {th }}$ order region and $5^{\text {th }}$ order regions; when the incident angle is greater than $0^{\circ}$, the fluid velocity is no longer symmetrical about the centreline of the workpiece rotation, and the fluid velocity at the lower end of the workpiece rotation centreline is greater than that at the upper end; when the incident angle is $90^{\circ}$, the workpiece has obvious plastic deformation; the larger the incident angle, the more collisions between the abrasive particles and the workpiece wall surface, the more favourable the abrasive particles to remove the workpiece material, the more favourable the precision processing effect of the abrasive flow.

(4) Before abrasive flow precision machining, the inner surface of the $5^{\text {th }}$ order variable-diameter pipe workpiece has many uneven spots and burrs, which are disorderly and diminish the surface quality. After abrasive flow precision machining, the streaky scratches on the surface of the $5^{\text {th }}$ order variable-diameter pipe workpiece are clearer, the spots and burrs on the workpiece surface disappear, the surface is smoother and the surface quality is obviously improved. 
The surface roughness of each order region after precision machining by abrasive flow is improved, and the surface finishing of the 3 rd order region is the best. The two-way machining can obtain a uniform surface better than one-way machining can, and can produce better surface quality.

\section{ACKNOWLEDGEMENTS}

The authors would like to thank the National Natural Science Foundation of China No. NSFC 51206011, Jilin Province Science and Technology Development Programme of Jilin province No. 20200301040RQ, Project of education department of Jilin province No. JJKH20190541KJ, Changchun Science and Technology programme No. 18DY017.

\section{REFERENCES}

[1] Petare, A.C., Kumar Jain, N. (2018). On simultaneous improvement of wear characteristics, surface finish and microgeometry of straight bevel gears by abrasive flow finishing process. Wear, vol. 404-405, p. 38-49, D0l:10.1016/j.wear.2018.03.002.

[2] Sankar, M.R., Jain, V.K., Ramkumar, J., Sareen, S.K., Singh, S. (2018). Medium rheological characterization and performance study during rotational abrasive flow finishing (R-AFF) of Al alloy and Al alloy/SiC MMCs. The International Journal of Advanced Manufacturing Technology, vol. 100, p. 1149-1163, DOI:10.1007/s00170-018-2244-y.

[3] Sambharia, J., Mali, H.S. (2019). Recent developments in abrasive flow finishing process: A review of current research and future prospects. Proceedings of the Institution of Mechanical Engineers, Part B: Journal of Engineering Manufacture, vol. 233, no. 2, p. 388-399, DOI:10.1177/0954405417731466.

[4] Petare, A.C., Mishra, A., Palani, I.A., Jain, N.K. (2019). Study of laser texturing assisted abrasive flow finishing for enhancing surface quality and microgeometry of spur gears. The International Journal of Advanced Manufacturing Technology, vol. 101, p. 785-799, Dol:10.1007/s00170-018-2944-3.

[5] Zhao, J., Jiang, E.Y., Qi, H., Ji, S.M., Chen, Z.Z. (2020). A novel polishing method for single-crystal silicon using the cavitation rotary abrasive flow. Precision Engineering, vol. 61, p. 72-81, DOI:10.1016/j.precisioneng.2019.10.002.

[6] Singh, S., Kumar, D., Sankar, M.R., Jain, V.K. (2019). Viscoelastic medium modeling and surface roughness simulation of microholes finished by abrasive flow finishing process. The International Journal of Advanced Manufacturing Technology, vol. 100, no. 5-8, p. 1165-1182, Dol:10.1007/ s00170-018-1912-2.

[7] Singh, P., Singh, L., Singh, S. (2020). Manufacturing and performance analysis of mechanically alloyed magnetic abrasives for magneto abrasive flow finishing. Journal of
Manufacturing Processes, vol. 50, p. 161-169, Dol:10.1016/j. jmapro.2019.12.033.

[8] Baraiya, R., Babbar, A., Jain, V., Gupta, D. (2020). In-situ simultaneous surface finishing using abrasive flow machining via novel fixture. Journal of Manufacturing Processes, vol. 50, p. 266-278, DOI:10.1016/J.jmapro.2019.12.051.

[9] Bouland, C., Urlea, V., Beaubier, K., Samoilenko, M., Brailovski, v. (2019). Abrasive flow machining of laser powder bed-fused parts: Numerical modeling and experimental validation. Journal of Materials Processing Technology, vol. 273, DOI:10.1016/j.jmattect.2019.116262.

[10] Singh, S., Sankar, M.R. (2020). Development of polymer abrasive medium for nanofinishing of microholes on surgical stainless steel using abrasive flow finishing process. Proceedings of the Institution of Mechanical Engineers, vol. 234, no. 3, p. 355-370, Dol:10.1177/0954405419883768.

[11] Han, S., Salvatore, F., Rech, J. (2019). Residual stress profiles induced by abrasive flow machining (AFM) in 15-5PH stainless steel internal channel surfaces. Journal of Materials Processing Technology, vol. 267, p. 348-358, D0l:10.1016/j. jmatprotec.2018.12.024.

[12] Kathiresan, S., Mohan, B. (2018). Experimental analysis of magneto rheological abrasive flow finishing process on AISI stainless steel 316L. Materials and Manufacturing Processes, vol. 33, no. 4, p. 422-432, DOl:10.1080/10426914.2017.127 9317.

[13] Duan, Y.F., Feng, Z.G. (2019). A new kinetic theory model of granular flows that incorporates particle stiffness. Physics of Fluids, vol. 31, no. 1, Dol:10.1063/1.5051034.

[14] Chen, Z.R., Yu, J.Q., Xue, D.M., Wang, Y., Zhang, Q., Ren, L.Q. (2018). An approach to and validation of maize-seedassembly modelling based on the discrete element method. Powder Technology, vol. 328, p. 167-183, D0l:10.1016/j. powertec.2017.12.007.

[15] Jebahi, M., Dau, F., lordanoff, I., Guin, J.P. (2017). Virial stressbased model to simulate the silica glass densification with the discrete element method. International Journal for Numerical Methods in Engineering, vol. 112, no. 13, p. 1909-1925, D0l:10.1002/nme.5589.

[16] Feng, Y.T., Zhao, T., Kato, J., Zhou, W. (2016). Towards stochastic discrete element modelling of spherical particles with surface roughness: A normal interaction law. Computer Methods in Applied Mechanics and Engineering, vol. 315, p. 247-272, DOI:10.1016/J.cma.2016.10.031.

[17] Zhou, L., Zhang, L.J., Shi, W.D., Agarwal, R., Li, W. (2018). Transient Computational Fluid Dynamics/Discrete Element Method Simulation of Gas-Solid Flow in a Spouted Bed and Its Validation by High-Speed Imaging Experiment. Journal of Energy Resources Technology - Transactions of the ASME, vol. 140, no. 1, Dol:10.1115/1.4037685.

[18] Munhoz, M.R., Dias, L.G., Breganon, R., Ribeiro, F.S.F., Goncalves, J.F.D., Hashimoto, E.M. (2020). Analysis of the surface roughness obtained by the abrasive flow machining process using an abrasive paste with oiticica oil. International Journal of Advanced Manufacturing Technology, vol. 106, no. 11-12, p. 5061-5070, D0I:10.1007/s 00170-019-04920-7.

[19] Liu, G.S., Zhang, X.M., Zang, X., Li, J.Y., Su, N.N. (2018). Study on whole factorial experiment of polishing the micro-hole in 
non-linear tubes by abrasive flow. Advances in Mechanical Engineering, vol. 10, no. 8, Dol:10.1177/1687814018794590.

[20] Shao, Y.Z., Cheng, K. (2019). Integrated modelling and analysis of micro-cutting mechanics with the precision surface generation in abrasive flow machining. International Journal of Advanced Manufacturing Technology, vol. 105, no. 11, p. 4571-4583, D0I:10.1007/s00170-019-03595-4.

[21] Mohanty, R., Mohanty, S., Mishra, B.K. (2016). Study of flow through a packed bed using discrete element method and computational fluid dynamics. Journal of the Taiwan Institute of Chemical Engineers, vol. 63, p. 71-80, D0l:10.1016/j. jtice.2016.03.025.

[22] Kim, K.J., Kim, Y.G., Kim, K.H. (2019). Deburring of Offset Hole Intersection with Abrasive Flow Machining. Transactions of the Korean Society of Mechanical Engineers A, vol. 43, no. 7, p. 507-511, DOI:10.3795/KSME-A.2019.43.7.507.

[23] Li, J.Y., Meng, W.Q., Dong, K., Zhang, X.M., Zhao, W.H. (2018). Study of Effect of Impacting Direction on Abrasive Nanometric Cutting Process with Molecular Dynamics. Nanoscale Research Letters, vol. 13, D0I:10.1186/s11671-017-2412-2.

[24] Tan, R.K., Zhao, X.S., Guo, S.S., Zou, X.C., He, Y., Geng, Y.Q., Hu, Z.J., Sun, T. (2020). Sustainable production of dry-ultra-precision machining of Ti-6Al-4V alloy using PCD tool under ultrasonic elliptical vibration-assisted cutting. Journal of Cleaner Production, vol. 248, D0l:10.1016/j. jclepro.2019.119254.

[25] Chetan, Ghosh, S., Rao, P.V. (2019). Comparison between sustainable cryogenic techniques and nano-MQL cooling mode in turning of nickel-based alloy. Journal of Cleaner Production, vol. 231, p. 1036-1049, D0l:10.1016/J.jclepro.2019.05.196.
[26] Saffman, P.G. (1965). The Lift on a Small Sphere in a Slow Shear. Journal of Fluid Mechanics, p. 385-400, D0l:10.1017/S 0022112065000824

[27] Ren, B., Zhong, W.Q., Chen, Y., Chen, X., Jin, B.S., Yuan, Z.L., Lu, Y. (2012). CFD-DEM simulation of spouting of cornshaped particles. Particuology, vol. 10, no. 5, p. 562-572, D0l:10.1016/J.partic.2012.03.011.

[28] de Lacalle, L.N.L., Lamikiz, A., Munoa, J., Salgado, M.A., Sanchez, J.A. (2006). Improving the high-speed finishing of forming tools for advanced high-strength steels (AHSS). International Journal of Advanced Manufacturing Technology, vol. 29, no. 1-2, p. 49-63, D0I:10.1007/s00170-004-2482-z.

[29] Zou, L., Huang, Y., Zhang, G.J., Cui, X.P. (2019). Feasibility study of a flexible grinding method for precision machining of the TiAl-based alloy. Materials and Manufacturing Processes, DOI:10.1080/10426914.2019.1628255.

[30] Guo, L., Zhang, X.R., Chen, S.B., Hui, J.Z. (2019). An Experimental Study on the Precision Abrasive Machining Process of Hard and Brittle Materials with Ultraviolet-Resin Bond Diamond Abrasive Tools. Materials, vol. 12, no. 1, DOl:10.3390/ma12010125.

[31] Wang, T.T., Chen, D., Zhang, W.H., An, L.L. (2019). Study on key parameters of a new abrasive flow machining (AFM) process for surface finishing. International Journal of Advanced Manufacturing Technology, vol. 101, no. 1-4, p. 39-54, D0l:10.1007/s00170-018-2914-9.

[32] Wei, H.B., Peng, C., Gao, H., Wang, X.P., Wang, X.Y. (2019). On establishment and validation of a new predictive model for material removal in abrasive flow machining. International Journal of Machine Tools and Manufacture, vol. 138, p. 6679, D0I:10.1016/j.ijmachtools.2018.12.003. 